\title{
Effect of Vitamin E Supplementation on Deposition and Gene Expression Profiling of Abdominal Fat in Broiler Chickens
}

\author{
Min Zhang ${ }^{1,2,3}$, Jianlei $\mathrm{Li}^{1}$, Yuting Zhu ${ }^{1}$, Qiong $\mathrm{Wu}^{1,2,3}$, Yan $\mathrm{Li}^{1,2,3}$, Dingrui Huang ${ }^{1}$, \\ Zhending Gan ${ }^{1}$, Lipeng Zhong ${ }^{1}$, Jingyu Huang ${ }^{1}$, Hongyi $\mathrm{Li}^{1,2,3}$, Weihua $\mathrm{Xu}^{1,2,3}$, \\ Mao Zhang ${ }^{1,2,3}$, Qichun Hung ${ }^{1,2,3}$ and Yanfa Sun ${ }^{1,2,3}$ \\ ${ }^{1}$ College of Life Science, Longyan University, Longyan, Fujian 364012, China \\ ${ }^{2}$ Fujian Provincial Key Laboratory for the Prevention and Control of Animal Infectious Diseases and Biotechnology, \\ Longyan, Fujian 364012, China \\ ${ }^{3}$ Key Laboratory of Preventive Veterinary Medicine and Biotechnology (Longyan University), \\ Longyan, Fujian 364012, China
}

\begin{abstract}
The aim of this study was to study the regulation of abdominal fat deposition by DL- $\alpha$-tocopherol acetate (vitamin E) in broilers. Diets supplemented with 50 IU vitamin E significantly diminished abdominal fat deposition in broilers at day 35. Transcriptome sequencing results for abdominal fat tissues of the control (FC) and 50 IU vitamin E-supplemented (FT) groups identified 602 differentially expressed genes (DEGs), which were enriched in cellular process, cell and cell part, and binding Gene Ontology terms. Pathway functional analysis revealed that the DEGs were enriched in 42 metabolic pathways. Notably, the most enriched pathway, fatty acid biosynthesis, was found to play a key role in lipid metabolism. Further, the key regulators of lipid metabolism, including fatty acid synthase, acetyl-CoA carboxylase alpha, and acyl-CoA synthetase long-chain family member 1, demonstrated decreased expression following vitamin E supplementation. Herein, we have identified pathways and genes regulated by vitamin E, thereby providing novel insights into the nutrients regulating abdominal fat deposition in broilers.
\end{abstract}

Key words: abdominal fat deposition, broiler, gene expression, RNA-seq, vitamin E

J. Poult. Sci., 58: 40-50, 2021

\section{Introduction}

Vitamin $\mathrm{E}$ is an essential micronutrient for humans and animals. There are eight fat-soluble vitamin $\mathrm{E}$ compounds $(\alpha-, \beta-, \gamma-$, and $\delta$-tocopherol and $\alpha-, \beta-, \gamma-$, and $\delta$-tocotrienol), with $\alpha$-tocopherol being one of the most active forms (Gonzalez-Calvo et al., 2017). Human and animal diets are commonly fortified with $\alpha$-tocopherol to meet basal nutritional requirements. Vitamin E plays vital roles in physiological processes, such as fertility, oxidative homeostasis, signal transduction, and gene regulation, and in diseases, such as non-alcoholic fatty liver. Clinical insights regarding the roles of vitamin $\mathrm{E}$ have been previously summarized

Received: February 14, 2020, Accepted: March 31, 2020

Released Online Advance Publication: June 25, 2020

Correspondence: Dr. Yanfa Sun, College of Life Science, Longyan University, No. 1 Dongxiao North Road, Xinluo District, Longyan, Fujian, China. (E-mail: boysun2010@163.com)

The Journal of Poultry Science is an Open Access journal distributed under the Creative Commons Attribution-NonCommercial-ShareAlike 4.0 International License. To view the details of this license, please visit (https:// creativecommons.org/licenses/by-nc-sa/4.0/).
(Galli et al., 2017). Recently, the role of vitamin E and its metabolites in regulating cell signaling and gene transcription have received increased attention (Azzi, et al., 2018). Moreover, the role of vitamin $\mathrm{E}$ in regulating lipid metabolism and abdominal fat deposition has also been investigated (Sun et al., 2015). Studies have shown that vitamin E supplementation can prevent human lipid metabolism-related diseases, such as non-alcoholic fatty liver (Oliveira et al., 2003; Sato et al., 2015) and diabetes (Yan et al., 2017; Alkholy et al., 2018), and improve insulin sensitivity in these patients (Gray et al., 2011). In animals, dietary vitamin E increased the levels of certain polyunsaturated fatty acids in muscle tissue, which led to a higher percentage of these molecules in long-term frozen contained meat (Ferrinho et al., 2018). Dietary vitamin $\mathrm{E}$ has also been shown to prevent diet-induced lipid accumulation in the liver of guinea pigs (Podszun et al., 2014). Moreover, dietary vitamin E supplementation decreased the amount of abdominal fat in broiler chickens (Li et al., 2009; Zaboli et al., 2013) and the same results were found under conditions of heat stress (Habibian et al., 2014).

The regulatory roles of vitamin E on lipid metabolism may 
involve inhibition of adipose cell conversion by regulating signaling pathways and modulating gene transcription. A previous study showed that vitamin $\mathrm{E}$ inhibited the adipose conversion of 3T3-L1 cells at micromolar levels (Kawada et al., 1900). Further studies indicated that vitamin E induced adiponectin expression in rat adipose tissues and 3T3-L1 cells via a peroxisome proliferator-activated receptor $\gamma$ dependent mechanism (Landrier et al., 2009). Adiponectin is important in lipid metabolism because it promotes adipocyte differentiation, insulin sensitivity, and lipid accumulation (Fu et al., 2005).

Vitamin E can also affect fat deposition by regulating the expression of genes involved in lipid metabolism, such as those involved in lipogenesis, lipolysis, and transport. In broilers, $200 \mathrm{mg} / \mathrm{kg}$ dietary vitamin E supplementation increases $P P A R-\beta$ and $H-F A B P$ expression in the pectoralis $(\mathrm{Li}$ et al., 2009). In light lambs, short-term $\alpha$-tocopherol treatment affected $A B C A 1, L P L, A P O E$, and $S R E B P 1$ expression in the L. thoracis (LT) muscle and ABCA1, SCARB1, LPL, and $P P A R G$ in subcutaneous fat (SF) cells; in contrast, PPARA expression was upregulated, but only after long-term $\alpha$-tocopherol treatment (Gonzalez-Calvo et al., 2014). A study that compared the gene expression profiles of lambs that received vitamin $\mathrm{E}$ ( $500 \mathrm{mg} / \mathrm{kg} \mathrm{DL}-\alpha$-tocopheryl acetate) and controls found that vitamin E supplementation dramatically affected the gene expression profile of SF cells; there was a general upregulation of significant genes compared to the control animals. Vitamin E supplementation caused a downregulation of genes related to intracellular signaling in the LT. Functional analysis of SF cells showed that vitamin E supplementation resulted in an upregulation of lipid, cholesterol, sterol, and steroid biosynthesis genes, and a downregulation of stress response genes (Gonzalez-Calvo et al., 2017). However, there have been few studies on the role of vitamin $\mathrm{E}$ in abdominal fat. Moreover, the regulatory mechanisms of vitamin $\mathrm{E}$ on lipid metabolism are incompletely understood.

In the chicken industry, broilers grown for meat have a fast growth rate; however, they often have excessive deposits of body fat, especially abdominal fat (Zaboli et al., 2013; Huang et al., 2015). Abdominal fat is highly correlated with total carcass lipids and is used as the main criterion for assessing excess fat deposition in broilers (Chambers et al., 2009). Dietary vitamin E ( $\alpha$-tocopherol acetate) supplementation has been shown to significantly decrease abdominal fat content (Li et al., 2009; Zaboli et al., 2013). Thus, chickens are an ideal model organism for studying abdominal obesity; therefore, we investigated the key genes and metabolic pathways associated with reduced abdominal fat deposits in broilers fed on a diet supplemented with dl- $\alpha$-tocopherol acetate using RNA sequencing (RNA-seq) to identify pathways that could be targeted to prevent obesity in humans.

\section{Materials and Methods}

\section{Animals, Experimental Design, and Diets}

This study was conducted in accordance with the Guidelines for Experimental Animals established by the Ministry
Table 1. Ingredients and chemical composition of basal diets for broilers ${ }^{1}$

\begin{tabular}{lcc}
\hline \multicolumn{1}{c}{ Item } & 0 to 21 days & 22 to 35 days \\
\hline Ingredients & & \\
Corn & 478.1 & 534.5 \\
Soybean meal & 318.1 & 281.7 \\
Wheat & 80.0 & 50.0 \\
Soybean oil & 51.2 & 60.8 \\
Corn gluten meal & 30.0 & 30.0 \\
Limestone & 12.3 & 11.0 \\
Dicalcium phosphate & 14.6 & 15.3 \\
DL-Methionine & 1.6 & 1.9 \\
L-Lysine & 1.1 & 1.8 \\
Salt & 3.0 & 3.0 \\
Premix & 10.0 & 10.0 \\
Total & 1000 & 1000 \\
Chemical composition & & \\
ME, MJ/kg & 12.98 & 13.36 \\
CP & 205.0 & 190.0 \\
Calcium & 9.0 & 8.5 \\
Available P & 4.5 & 4.5 \\
Lysine & 10.5 & 10.2 \\
Methionine & 4.5 & 4.5 \\
Vitamin E, IU & 82.4 & 90.1 \\
Ner & &
\end{tabular}

Note: ${ }^{1}$ Provided per kg of premix: Se $\left(\mathrm{Na}_{2} \mathrm{SeO}_{3}\right) 0.3 \mathrm{mg}, \mathrm{Cu}$ $\left(\mathrm{CuSO}_{4}\right) 10 \mathrm{mg}, \mathrm{Mn}\left(\mathrm{MnSO}_{4}\right) 60 \mathrm{mg}, \mathrm{Zn}\left(\mathrm{ZnSO}_{4}\right) 120 \mathrm{mg}, \mathrm{Fe}\left(\mathrm{Fe}_{2}\right.$ (SO4) $)_{3} 60 \mathrm{mg}, \mathrm{VA} 10000 \mathrm{IU}, \mathrm{VD}_{3} 3500 \mathrm{IU}, \mathrm{VK}_{3} 5000 \mathrm{IU}, \mathrm{VB}_{1} 2$ $\mathrm{mg}, \mathrm{VB}_{2} 5 \mathrm{mg}, \mathrm{VB}_{6} 4 \mathrm{mg}, \mathrm{VB}_{12} 0.04 \mathrm{mg}$, biotin $0.20 \mathrm{mg}$, folic acid $2.0 \mathrm{mg}$, niacin $40 \mathrm{mg}$, calcium pantothenate $20 \mathrm{mg}$.

${ }^{2}$ Vitmian E is DL- $\alpha$-tocopheryl acetate, $1 \mathrm{mg} \mathrm{DL}-\alpha$-tocopheryl acetate $=1 \mathrm{IU}$ alpha-tocopherol; the values in nutrient levels of the diet are calculated except VE.

of Science and Technology (Beijing, China). A total of 240 1-day-old healthy female chicks, which had no significant differences in birth weight between each treatment (42.35土 $1.92 \mathrm{~g}, P>0.05)$, were randomly allocated into five dietary treatments. Each treatment had six replicates and each replicate had eight chicks. The two period ( $0-21$ days and 22-35 days) corn/soybean meal basal diet was provided. The basal diet composition is shown in Table 1. The vitamin E ( $\alpha$-tocopherol) concentrations in the diet were measured as previously described (Li et al., 2009). The diet contained 82.4 and $90.1 \mathrm{IU}$ vitamin $\mathrm{E}$ in the $0-21$ day and 22-35 day periods, respectively. Chickens from the five treatment groups were fed on a basal diet supplemented with $0,20,50$, 75 , and $100 \mathrm{IU}$ dietary DL- $\alpha$-tocopheryl acetate (vitamin E, 1 mg DL- $\alpha$-tocopheryl acetate $=1 \mathrm{IU}$ alpha-tocopherol, Xinchang Hebao Biotechnology Co. Ltd, Xinchang, China) over the 35-d trial period. All broilers were raised in stair-step cages with ad libitum access to feed and fresh water under the recommended environmental settings according to the normal management practices at the Animal Feeding Room of Longyan University. Broilers were conventionally vaccinated for Marek's disease at birth, Newcastle disease and infectious bronchitis at days 7 and 21, and infectious bursal disease at day 14 . 


\section{Samples and Measurements}

At the end of each trial period, all broilers were weighed after fasting for $12 \mathrm{~h}$. One broiler from each replicate was randomly selected, weighed and killed by stunning and exsanguination after $12 \mathrm{~h}$ of fasting. The abdominal fat was weighed as previously described (Li et al., 2009; Sun et al., 2013), and samples were stored at $-20^{\circ} \mathrm{C}$ or in liquid nitrogen until further use. Because there were greater abdominal fat weight (AFW) differences between the $50 \mathrm{IU}$ vitamin $\mathrm{E}$ group and controls, three abdominal fat tissue samples from the control group (FC) and three from 50 IU vitamin E treatment group (FT) were used for further study.

Before euthanasia, blood was collected from the brachial vein of one broiler from each replicate by venipuncture, and the sera of these broilers were separated by centrifugation at $2,000 \mathrm{rpm}$ for $5 \mathrm{~min}$ at $25^{\circ} \mathrm{C}$ and frozen at $-80^{\circ} \mathrm{C}$. Serum $\alpha-$ tocopherol levels were measured using assay kits purchased from Nanjing Jiancheng Bioengineering Institute (Nanjing, China) according to the manufacturer's instructions.

\section{mRNA Library Construction and Sequencing}

Total RNA was isolated from abdominal fat tissue using the RNAsimple Total RNA kit (Tiangen Biotech Inc., Beijing, China) in accordance with the manufacturer's instructions. RNA integrity and concentrations were evaluated using an Agilent 2100 Bio-analyzer (Agilent Technologies, Palo Alto, CA, USA), and the RNA was treated with Ambion DNase I (Life Technologies Inc., Carlsbad, CA, USA) following the manufacturer's instructions. The average RNA integrity number (RIN) of each sample was 9.1, indicating sufficient quality for transcriptome sequencing. The mRNA was enriched from total RNA samples using oligo (DT) magnetic beads (Invitrogen, Carlsbad, CA, USA). Purified mRNA was first fragmented using an RNA fragmentation kit (Ambion, Austin, TX, USA), and then first-strand cDNA was synthesized. Subsequently, second-strand cDNAs were synthesized according to the manufacturer's instructions. The cDNA library was assessed on the Agilent 2100 Bioanalyzer and the ABI Step One Plus Real-Time PCR System. Final cDNA libraries were sequenced using the Illumina HiSeq 2500 system.

\section{RNA-seq Data Processing and Analysis}

Raw reads of each sample were obtained by Illumina sequencing. Clean reads omitted the low-quality reads and reads with adaptors and unknown bases using SOAPnuke v1.5.2 (Chen et al., 2018). Clean reads were mapped to the chicken reference genome using HISAT2 v2.0.4 (Kim et al., 2015). The mapping rate of the genes was statistically accurate, suggesting clean reads mapped to the chicken reference genome using Bowtie2 v2.2.5 (Langmead et al., 2012); expression levels were calculated by RSEM v1.2.12 (Li et al., 2011). A heatmap of all expressed genes was created in R v3.4.3 using the pheatmap package. Differentially expressed genes (DEGs) between the FC and the FT groups were identified using the DESeq2 method (Love et al., 2014). Genes with an absolute value of $\log 2$ (FT/FC) fold change $\geq 2.00$ and an adjusted $P$-value $\leq 0.05$ were considered to be DEGs in this study.

\section{Gene Ontology (GO) and Kyoto Encyclopedia of Genes and Genomes (KEGG)pathway Analysis}

$\mathrm{GO}$ analysis for DEGs between the FC and FT groups was performed using Blast2GO, a software package that retrieves GO terms (Götz et al., 2008). The significance level of the GO terms was set as false discovery rate-adjusted $P$-values $\leq 0.05$. The KEGG ontology (KO) enrichment analyses for the DEGs were performed to further elucidate their biological functions. In all tests, $P$-values were calculated using the Benjamini and Hochberg FDR correction test and $P$ values $\leq 0.05$ were considered to be statistically significant.

Validation of RNA-seq Results using Quantitative Realtime PCR (qPCR)

To validate the repeatability and reproducibility of the gene expression data, quantitative real-time PCR (qPCR) of nine selected DEGs was performed. $\beta$-actin was used as a reference gene. All primer sequences were designed using Primer Premier 5 software (Premier Biosoft, Palo Alto, CA, USA). Total RNA was isolated from abdominal fat tissue with the RNAsimple Total RNA kit (Tiangen Biotech, Beijing, China). First-strand cDNA was synthesized from $2 \mu \mathrm{g}$ total RNA using the Reverse Transcription Kit (Promega, Beijing, China). Power SYBR ${ }^{\circledR G r e e n}$ PCR Master Mix (Applied Biosystems) was used to analyze mRNA levels of selected genes. Next, qPCRs were performed on an ABI 7500 Real-time Detection System (Applied Biosystems). Amplification was performed in a total volume of $20 \mu \mathrm{L}$ containing $10 \mu \mathrm{L}$ of 2 $\times$ PCR Master Mix, $100 \mathrm{ng}$ cDNA, $0.5 \mu \mathrm{L}$ of each primer $(10 \mu \mathrm{mol})$, and $8.0 \mu \mathrm{L} \mathrm{ddH} 2 \mathrm{O}$. To ensure similar PCR efficiencies (close to 100\%) between target genes and the reference gene $(\beta$-actin), primer and cDNA concentrations were optimized as needed. The following PCR conditions were used: $95^{\circ} \mathrm{C}$ for $10 \mathrm{mins}$, followed by 40 cycles of $95^{\circ} \mathrm{C}$ for $15 \mathrm{~s}, 60^{\circ} \mathrm{C}$ for $20 \mathrm{~s}$ and $72^{\circ} \mathrm{C}$ for $32 \mathrm{~s}$. To determine fold changes in gene expression, the comparative $\mathrm{CT}$ method was used (Livak et al., 2001), calculated as $2^{\text {-Liva }}$. The results are expressed as the mean fold change in gene expression from triplicate analyses.

\section{Statistical Analysis}

The statistical analysis of growth performance, carcass performance, and serum $\alpha$-tocopherol concentrations between the treatments were performed with one-way analysis of variance (ANOVA) using SPSS, version 19.0 (IBM, Armonk, NY, USA), and the results are expressed as mean and pooled square estimated margin (SEM). Differences were tested at levels of significance of 0.05 and 0.01 with the least significant difference (LSD) multiple comparisons method. Statistical analyses of gene expression levels between the FC and FT groups were performed with independent-sample $T$ test using SPSS v19.0. Differences were tested at a level of significance of 0.05 with the $t$ statistic.

\section{Results}

\section{Growth Performance, Fat Deposition, and Serum Vitamin E Content}

For the growth performance, only $\mathrm{F} / \mathrm{G}$ was significantly increased after 5 weeks of $25 \mathrm{IU}$ vitamin E treatment com- 
Table 2. Effect of dietary vitamin $\mathbf{E}$ levels on growth performance in broilers ${ }^{1}$

\begin{tabular}{|c|c|c|c|c|c|c|c|}
\hline \multirow{2}{*}{ Item $^{3}$} & \multicolumn{5}{|c|}{ Vitamin E levels ${ }^{2}$} & \multirow{2}{*}{$P$-value } & \multirow{2}{*}{ Pooled SEM } \\
\hline & $0 \mathrm{IU}$ & $25 \mathrm{IU}$ & $50 \mathrm{IU}$ & $75 \mathrm{IU}$ & $100 \mathrm{IU}$ & & \\
\hline \multicolumn{8}{|l|}{7 days } \\
\hline ADG (g/day) & 14.23 & 14.79 & 14.04 & 14.82 & 14.70 & 0.1958 & 0.05 \\
\hline ADFI (g/day) & 18.23 & 17.50 & 16.90 & 17.59 & 18.08 & 0.3621 & 0.19 \\
\hline $\mathrm{F} / \mathrm{G}$ & 1.29 & 1.18 & 1.20 & 1.19 & 1.23 & 0.2648 & 0.00 \\
\hline \multicolumn{8}{|l|}{14 days } \\
\hline ADG (g/day) & 28.37 & 28.05 & 27.09 & 28.67 & 27.66 & 0.4281 & 0.28 \\
\hline ADFI (g/day) & 41.13 & 43.76 & 39.81 & 43.52 & 41.00 & 0.0535 & 0.66 \\
\hline $\mathrm{F} / \mathrm{G}$ & 1.51 & 1.56 & 1.51 & 1.52 & 1.48 & 0.1653 & 0.00 \\
\hline \multicolumn{8}{|l|}{21 days } \\
\hline ADG (g/day) & 40.56 & 39.67 & 40.46 & 42.17 & 39.86 & 0.4578 & 0.92 \\
\hline ADFI (g/day) & 69.69 & 66.78 & 65.73 & 67.86 & 65.14 & 0.5881 & 3.99 \\
\hline $\mathrm{F} / \mathrm{G}$ & 1.72 & 1.69 & 1.63 & 1.61 & 1.64 & 0.5873 & 0.00 \\
\hline \multicolumn{8}{|l|}{28 days } \\
\hline ADG (g/day) & 61.96 & 61.92 & 59.38 & 59.53 & 61.45 & 0.7890 & 3.20 \\
\hline ADFI (g/day) & 92.51 & 90.1 & 91.92 & 96.25 & 89.86 & 0.7904 & 13.46 \\
\hline $\mathrm{F} / \mathrm{G}$ & 1.49 & 1.46 & 1.55 & 1.62 & 1.46 & 0.1088 & 0.00 \\
\hline \multicolumn{8}{|l|}{35 days } \\
\hline ADG (g/day) & 68.04 & 68.89 & 73.8 & 70.46 & 74.62 & 0.3458 & 6.30 \\
\hline ADFI (g/day) & 125.88 & 142.11 & 140.01 & 137.43 & 143.52 & 0.1066 & 19.91 \\
\hline $\mathrm{F} / \mathrm{G}$ & $1.85^{\mathrm{b}}$ & $2.08^{\mathrm{a}}$ & $1.90^{\mathrm{b}}$ & $1.95^{\mathrm{ab}}$ & $1.93^{\mathrm{ab}}$ & 0.0382 & 0.00 \\
\hline
\end{tabular}

Note: ${ }^{1}$ Data are means and pooled SEM $(n=6)$; different lowercase superscripts in each column indicate significant differences.

${ }^{2}$ Vitmian E is DL- $\alpha$-tocopheryl acetate, $1 \mathrm{mg}$ DL- $\alpha$-tocopheryl acetate $=1$ IU alpha-tocopherol.

${ }^{3} \mathrm{ADG}$, average daily gain; ADFI, average daily feed intake; $\mathrm{F} / \mathrm{G}$, feed/gain ratio.

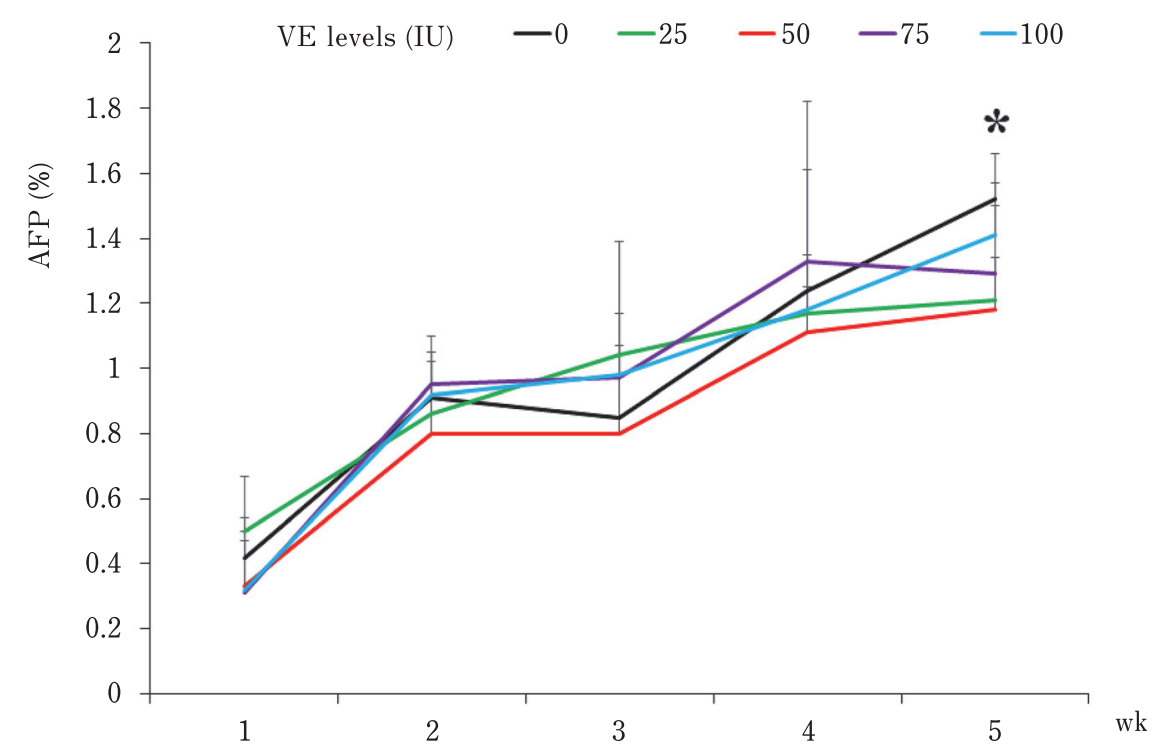

Fig. 1. Effect of dietary vitamin $\mathbf{E}$ supplementation on abdominal fat deposition in broilers.

pared to the control $(P<0.05$; Table 2$)$. Abdominal fat deposition was significantly decreased after 5 weeks of 25 or 50 IU vitamin $\mathrm{E}$ treatment compared to the control $(P<0.05$; Fig. 1 and Table S1). Serum $\alpha$-tocopherol levels were significantly higher in broilers that received vitamin E supplementation compared to the controls $(P<0.05$; Table 3$)$.

\section{Mapping and Counting Reads}

Approximately $44 \mathrm{Mb}$ clean reads for each sample, with the percentages of mapped reads ranging from $73.10 \%$ to $76.53 \%$, were obtained after raw data quality control. There were similar clean reads and percentages of mapped reads in the FC and FT groups (Table 4). The total number of genes and transcripts in the six abdominal fat samples ranged from 
Table 3. Effect of dietary vitamin $\mathbf{E}$ levels on serum vitamin $\mathbf{E}$ contents in broilers ${ }^{1}$

\begin{tabular}{|c|c|c|c|c|c|c|c|}
\hline \multirow{2}{*}{ Items } & \multicolumn{5}{|c|}{ Vitamin E levels ${ }^{2}$} & \multirow{2}{*}{$P$-value } & \multirow{2}{*}{ Pooled SEM } \\
\hline & $0 \mathrm{IU}$ & $25 \mathrm{IU}$ & $50 \mathrm{IU}$ & $75 \mathrm{IU}$ & $100 \mathrm{IU}$ & & \\
\hline 7 days & $20.71^{\mathrm{d}}$ & $31.51^{\mathrm{a}}$ & $29.17^{\mathrm{ab}}$ & $25.76^{\mathrm{bc}}$ & $22.9^{\mathrm{dc}}$ & 0.00 & 1.43 \\
\hline 14 days & $16.68^{\mathrm{bc}}$ & $15.83^{\mathrm{bc}}$ & $17.68^{\mathrm{ab}}$ & $14.73^{\mathrm{c}}$ & $19.49^{\mathrm{a}}$ & 0.00 & 0.73 \\
\hline 21 days & $13.54^{\mathrm{b}}$ & $18.85^{\mathrm{a}}$ & $18.78^{\mathrm{a}}$ & $16.85^{\mathrm{ab}}$ & $15.22^{\mathrm{ab}}$ & 0.00 & 1.33 \\
\hline 28 days & $13.29^{\mathrm{c}}$ & $15.8^{\mathrm{ab}}$ & $17.12^{\mathrm{a}}$ & $14.71^{\mathrm{bc}}$ & $15.83^{\mathrm{ab}}$ & 0.00 & 0.62 \\
\hline 35 days & $13.35^{\mathrm{c}}$ & $16.78^{\mathrm{b}}$ & $16.16^{\mathrm{b}}$ & $17.04^{\mathrm{ab}}$ & $16.81^{\mathrm{a}}$ & 0.00 & 0.41 \\
\hline
\end{tabular}

Note: ${ }^{1}$ Data are means and pooled SEM $(n=6)$; different lowercase superscripts in each column indicate significant differences.

${ }^{2}$ Vitmian E is DL- $\alpha$-tocopheryl acetate, $1 \mathrm{mg}$ DL- $\alpha$-tocopheryl acetate $=1 \mathrm{IU}$ alpha-tocopherol.

Table 4. Number of reads obtained and percentage of mapped reads per sample

\begin{tabular}{cccc}
\hline \hline Sample ID $^{1}$ & ${\text { Total clean reads }(\mathrm{Mb})^{2}}^{2}$ & Clean reads ratio $(\%)$ & ${\text { Total mapping ratio }(\%)^{3}}^{3}$ \\
\hline FC1 & 44.08 & 74.78 & 76.51 \\
FC2 & 44.64 & 75.73 & 74.13 \\
FC3 & 44.92 & 76.20 & 73.49 \\
FT1 & 44.90 & 76.17 & 73.75 \\
FT2 & 44.54 & 73.52 & 74.60 \\
FT3 & 44.61 & 73.63 & 73.10 \\
\hline
\end{tabular}

Note: ${ }^{1}$ FC1, FC2, FC3 and FT1, FT2, FT3 are from the abdominal fat tissues of broilers in 5th week control group (FC) and $50 \mathrm{IU}$ vitamin E treatment group (FT), respectively.

${ }^{2}$ The clean data obtained after quality control.

${ }^{3}$ The clean reads mapped on the reference genome.

Table 5. The number of genes and transcripts per sample

\begin{tabular}{lrrrrrrr}
\hline \multicolumn{1}{c}{ Sample ID } & FC1 & FC2 & FC3 & FT1 & FT2 & FT3 & $P$-value \\
\hline Total gene number & 16055 & 16224 & 15945 & 15828 & 15600 & 15661 & 0.023 \\
Known gene number & 15301 & 15485 & 15217 & 15082 & 14862 & 14936 & 0.022 \\
Novel gene number & 754 & 739 & 728 & 746 & 738 & 725 & 0.701 \\
Total transcript number & 33571 & 33997 & 31314 & 30705 & 30363 & 30200 & 0.089 \\
Known transcript number & 24462 & 24896 & 22703 & 22182 & 21944 & 21757 & 0.087 \\
Novel transcript number & 9109 & 9101 & 8611 & 8523 & 8419 & 8443 & 0.096 \\
\hline
\end{tabular}

Note: ${ }^{1} P$-value from the independent-samples t-test between the FC and FT groups.

15600 16224 and 30200 33997, respectively (Table 5 and Table S2). The total gene number and known gene number in the FC group were greater than in the FT group $(P<0.05)$, but the total transcript number between the FC and FT groups were not significantly different $(P>0.05)$. Sequence data that support the findings of this study have been deposited in the NCBI Gene Expression Omnibus (GEO) data repository under the primary accession code, GSE113170.

Analysis of DEGs

A total of 602 DEGs were identified between the FC and FT groups (Table S3). Compared to the FC group, there were 126 upregulated genes and 476 downregulated genes in the FT group (Fig. 2 and Table S3). Cluster analysis between biological replicates showed that the samples formed two distinct groups, FC and FT, and indicated that the DEGs were very highly reproducible in replicate samples (Fig. 3).

\section{Functional Enrichment Analysis of the Identified DEGs}

$\mathrm{GO}$ analysis was performed for the up- and downregulated DEGs to identify differences in gene expression in the vitamin E group that could regulate abdominal fat deposition. DEGs were found in three ontologies with 50 GO terms, including biological process, cellular component, and molecular function (Fig. 4 and Table S4). The functions of most DEGs were cellular processes, single-cell organism processes, and cell-cell adhesion.

Following pathway function analysis of the DEGs, a total of 42 signaling pathways were identified $(P<0.05$; Table $\mathrm{S} 5)$. The DEGs were mainly enriched for metabolism, organismal systems, environmental information processing, human diseases, and cellular processes. The 11 lipid metabolism-related pathways with 83 DEGs are shown in Table 6. Among these metabolic pathways, fatty acid biosynthesis and glycerolipid metabolism are vital lipid metabolism path- 


\section{Scatter plot of FC-VS-FT.DEseq2_Method}

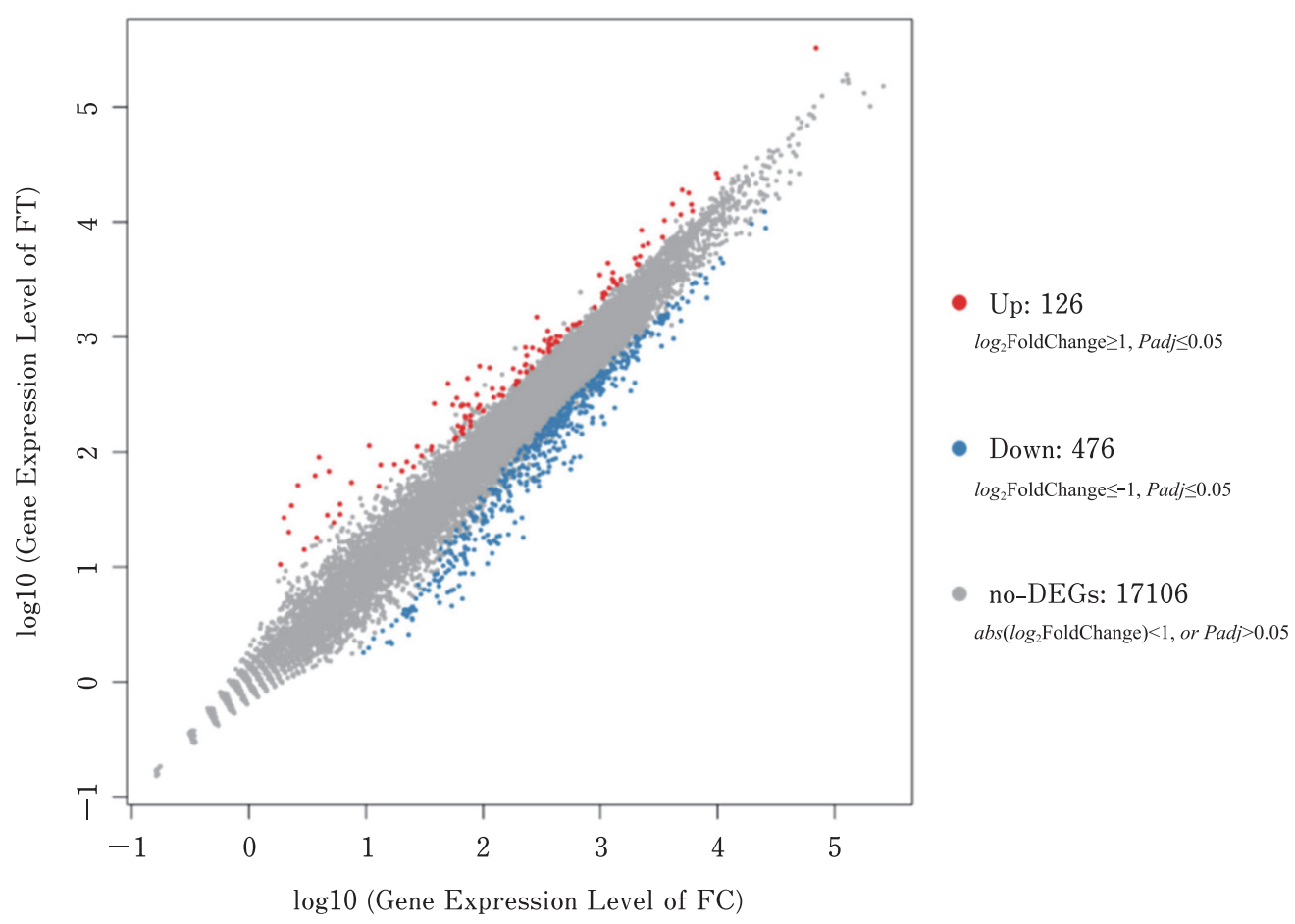

Fig. 2. Gene expression between the FC and FT groups. Compared with the FC group, there were 126 upregulated genes and 476 downregulated genes in the FT group.

\section{Pheatmap for FC\&FT}

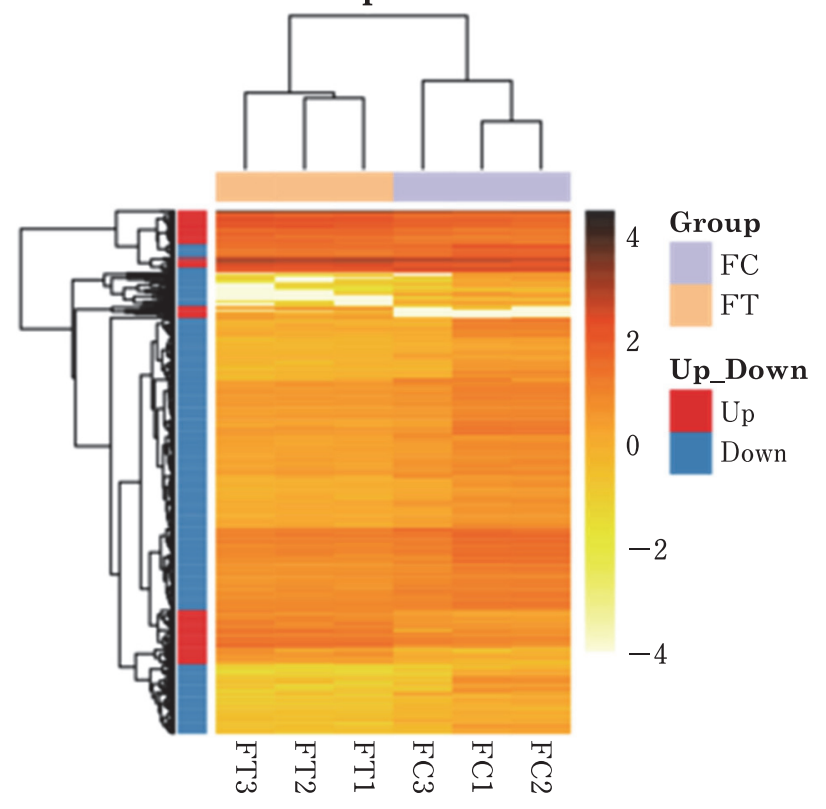

Fig. 3. Gene Ontology (GO) analysis results for differentially expressed genes (DEGs) in the FC and FT groups. GO analysis was performed for the up- and downregulated DEGs to identify differences in gene expression in the vitamin E group that could regulate abdominal fat deposition. The DEGs were found in three ontologies with 50 GO terms, including biological process, cellular component, and molecular function.

ways for lipogenesis; insulin resistance, and insulin signaling and have important roles in lipid metabolism. Some of the DEGs in the lipid metabolism-related pathways were important regulated-genes, such as, fatty acid synthase $(F A S N)$, acetyl-CoA carboxylase alpha $(A C A C A)$, and cAMP responsive element binding protein 5 (CREB5).

\section{qPCR Validation of RNA-seq Data}

Nine DEGs in the lipid metabolism-related pathways were selected to validate the RNA-seq results by qPCR. All primer sequences are listed in Table S6. All of the selected genes (FASN, ACACA, ACSL1, LOC100858678, FOS, FGFR3, MAP3K1, ATP2A3, and LPIN1) showed results consistent with the RNA-seq analysis (Table 7). Thus, our qPCR data confirmed the RNA-seq results, at least for the eight selected lipid metabolism genes. 


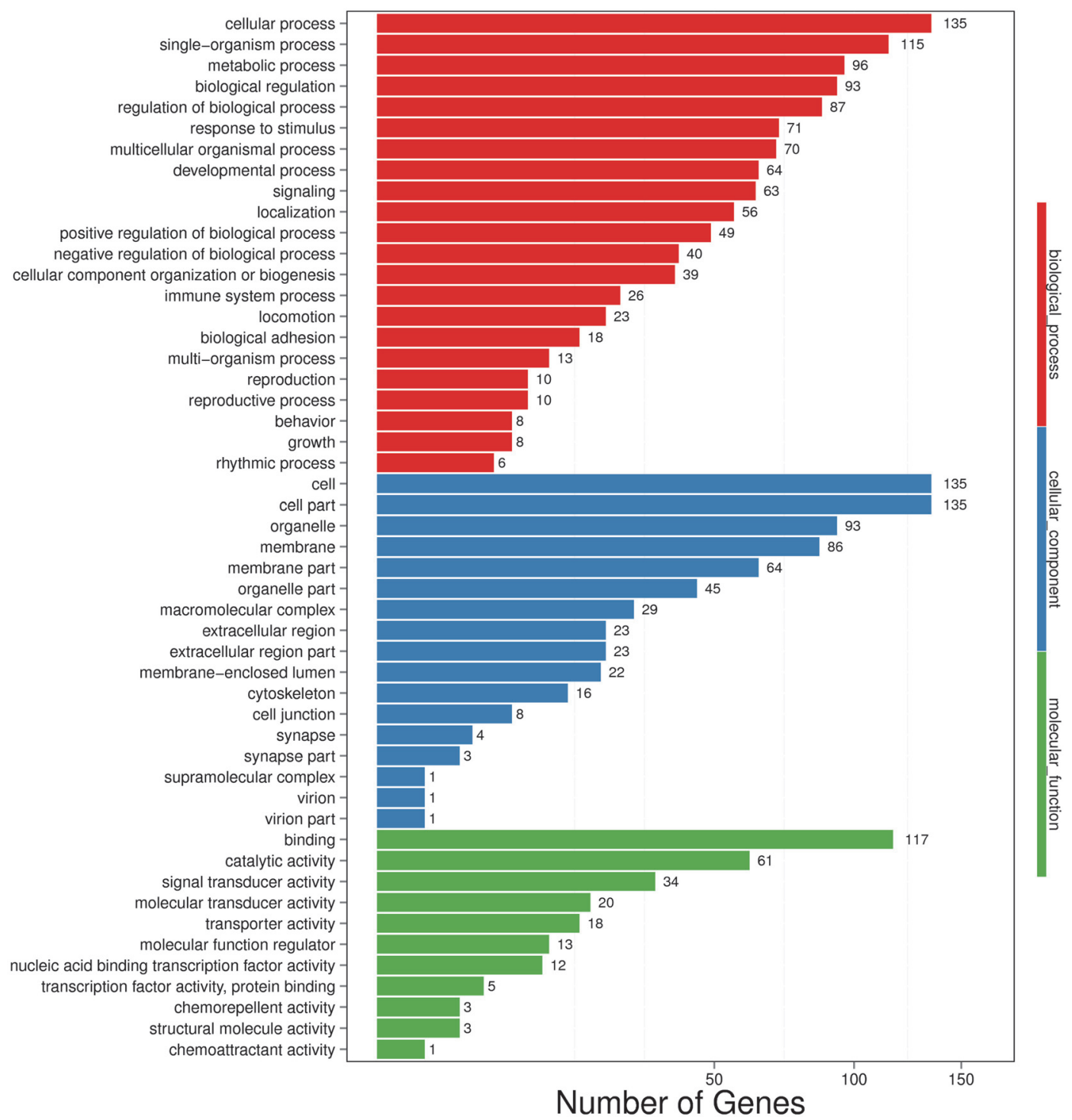

Fig. 4. Heatmap of hierarchical clustering of differentially expressed genes (DEGs). $\mathrm{X}$ axis represents the comparisons for clustering analysis; Y axis represents the DEGs. Colors indicate log2-transformed fold change (high: red; low: blue).

\section{Discussion}

Obesity causes adverse health outcomes in humans, and similar problems exist in chickens (Jin et al., 2017). Excessive abdominal fat accumulates in chickens, making them an ideal model organism for studying obesity-associated metabolic changes. Adipose tissue not only maintains energy balance, but also functions as a crucial endocrine organ that controls lipid metabolism (Jin et al., 2017). Female broilers were used in this study because they accumulate more fat than their male counterparts and they continuously deposit abdominal fat after hatching (Bai et al., 2015). Previously, several studies have used transcriptional analyses of abdominal fat from chickens to determine active signaling pathways and divergent gene expression for different trial objectives (Duan et al., 2013; Resnyk et al., 2015; Resnyk et al., 2017; Zhuo et al., 2015). Such studies have shown that vitamin $\mathrm{E}$ can modulate gene expression. Among the eight fat-soluble vitamin E compounds, $\alpha$-tocopherol is the most bioactive (Sun et al., 2015), and DL- $\alpha$-tocopherol acetate is commonly used as a source of vitamin $\mathrm{E}$ in the diets of broilers. The aim of this study was to use RNA-seq to reveal key metabolic pathways and genes that regulate abdominal fat deposition in broilers that were fed a diet supplemented with DL- $\alpha$-tocopherol acetate in an effort to provide a global reference that could be used to prevent excessive obesity in broilers.

A meta-analysis indicated that there was no relationship 
Table 6. Lipid metabolism-related pathways represented by DEGs

\begin{tabular}{|c|c|c|}
\hline Pathways & ID & Genes $^{1}$ \\
\hline Fatty acid biosynthesis & ko00061 & FASN, ACACA, ACSL1, LOC100858678 \\
\hline Insulin resistance & ko04931 & $\begin{array}{l}\text { FOXO1, PTPN11, PRKCB, MLXIP, TMTC4, OGT, C2CD2L, CREB5, } \\
\text { LOC100858678, LOC101749060, LOC107048989, LOC107049310 }\end{array}$ \\
\hline MAPK signaling pathway & ko04010 & $\begin{array}{l}\text { CACNB4, PPP3CA, FGFR4, FOS, FGFR3, SYNGR3, PRKCB, RALGPS1, } \\
\text { NALCN, PRDM16, AMHR2, TNIK, MAP3K1, GADD45B, GADD45A, } \\
\text { MEF2C, LOC107049310, LOC107050212, LOC107050551, LOC107053420, } \\
\text { LOC107056101 }\end{array}$ \\
\hline Glycerolipid metabolism & ko00561 & PNPLA3, LPIN1, EFCAB4B, PPAP2A, LIPC, FAM126B, LOC107049382 \\
\hline Insulin signaling pathway & ko04910 & $\begin{array}{l}\text { FOXO1, FASN, ACACA, RALGPS1, ANKS1A, RALGAPA1, SORBS1, } \\
\text { LOC100858678, PRKAR2A, LOC101749060, LOC107053420, LOC107056101, } \\
\text { LOC107057135 }\end{array}$ \\
\hline Thyroid hormone signaling pathway & ko04919 & $\begin{array}{l}\text { FOXO1, NOTCH1, ANOS1, ITGAV, PRKCB, NCOA3, PLCB2, RALGAPA1, } \\
\text { PLCE1, GSE1, PLCB1, KAT2B, LOC107053420 }\end{array}$ \\
\hline Apelin signaling pathway & ko04371 & $\begin{array}{l}\text { HDAC4, SMAD3, NOV }, \text { PIK3CG, PLCB2, PLCB1, MEF } 2 D, M E F 2 C, \\
J A G 2, L O C 101748756, \text { LOC107048989, LOC107050621, LOC107053420 }\end{array}$ \\
\hline mTOR signaling pathway & ko04150 & $\begin{array}{l}\text { FZD4, FZD1, PRKCB, RALGPS1, ENOX1, RNF152, FNIP2, RALGAPA1, } \\
\text { RICTOR, LOC107049310, LOC107053420, DDIT4, LOC107056101 }\end{array}$ \\
\hline Calcium signaling pathway & ko04020 & $\begin{array}{l}\text { PPP } 3 C A, A T P 2 A 3, P R K C B, N A L C N, A T P 2 B 4, P L C B 2, \text { HTR } 7, \text { PLCE1, } \\
\text { ADRB2, PLCB1, CYSLTR2, NTSR1, PTGER3, PDE1B, LOC101748756, } \\
\text { LOC107048989, LOC107050621 }\end{array}$ \\
\hline Estrogen signaling pathway & ko04915 & $\begin{array}{l}\text { FOS, RALGPS1, FKBP5, PLCB2, PLCB1, CREB5, LOC107048989, } \\
\text { LOC107053420, LOC107056101 }\end{array}$ \\
\hline Phospholipase D signaling pathway & ko04072 & $\begin{array}{l}\text { PTPN11, KITLG, IL8L2, RALGPS1, PIK3CG, GAB2, PLCB2, RALGAPA1, } \\
\text { PPAP2A, PLCB1, CXCR1, LOC107053420, LOC107056101 }\end{array}$ \\
\hline
\end{tabular}

${ }^{1}$ New gene IDs are not shown.

Table 7. Verification of RNA-seq data in abdominal fat from the control and vitamin E-supplemented groups

\begin{tabular}{cccccr}
\hline \hline \multirow{2}{*}{ Gene name } & \multicolumn{2}{c}{ RNA-seq } & & \multicolumn{2}{c}{ qPCR } \\
\cline { 2 - 3 } \cline { 5 - 6 } & Fold change & Adjusted P-value & & Fold change & P-value \\
\hline FASN & -1.43 & $<0.001$ & & -3.28 & 0.004 \\
ACACA & -1.82 & 0.001 & & -1.82 & 0.001 \\
ACSL1 & -1.55 & $<0.001$ & & -2.92 & 0.003 \\
LOC100858678 & -2.37 & 0.035 & & -4.63 & $<0.001$ \\
FOS & 1.79 & $<0.001$ & & 3.42 & 0.010 \\
FGFR3 & -1.71 & 0.022 & & -1.01 & 0.003 \\
MAP3K1 & -1.27 & 0.012 & & -2.82 & 0.002 \\
ATP2A3 & -1.10 & 0.034 & & -1.85 & 0.036 \\
LPIN1 & 1.20 & 0.032 & & 3.80 & 0.019 \\
\hline
\end{tabular}

between dietary vitamin E supplementation and growth performance in broilers (Pompeu et al., 2018), which was consistent with the findings of our study. Another study showed that vitamin E supplementation tended to improve growth and feed utilization during the first $0-3$ weeks, while performance from $0-5$ weeks was not influenced (Guo et al., 2001), possibly because responses to continuous vitamin $\mathrm{E}$ feeding are influenced by genetic stock, age, duration of feeding, and measurement criteria (Siegel et al., 2001). Vitamin E supplementation has consistently been shown to reduce the abdominal fat content in broilers (Li et al., 2009; Zaboli et al., 2013), which is consistent with the findings of this study. Because the effect of vitamin E needs to be ac- cumulated, the abdominal fat deposition of broilers decreased until the fifth week.

Through RNA-seq analysis, we identified 11 lipid metabolism-related pathways that were regulated by vitamin $\mathrm{E}$ and themselves could regulate abdominal fat deposition in broilers. We found two particularly noteworthy lipid metabolism pathways, fatty acid biosynthesis and glycerolipid metabolism, which have been proven to have essential functions in lipogenesis and lipolysis. We identified four genes in the fatty acid biosynthesis pathway that were downregulated following vitamin $\mathrm{E}$ treatment: $F A S N, A C A C A$, $A C S L 1$, and LOC100858678. FASN and ACACA are also in the insulin signaling pathway, and their protein products are 
the rate-limiting steps in de novo fatty acid synthesis. FASN is a multifunctional enzyme, that primarily catalyzes de novo saturated fatty acid synthesis and regulates lipid metabolism (Wakil et al., 1989; Niranjan et al., 2016). In chickens, an association study of two single nucleotide polymorphisms (SNPs) of FASN and abdominal fat traits was performed using an F2-designed resource population, and the results indicated that individuals with the BB genotype had a higher fat deposition capacity than other SNPs in the Hae III site; when heterozygotes of the two genotypes were tested, individuals with a BC/GG genotype had the highest fat deposition capacity (Ouyang et al., 2007). Through comparative genomic approaches, important candidate lipid metabolismrelated genes were identified, including FASN (Bakhtiarizadeh et al., 2013). ACACA encodes acetyl-coenzyme A carboxylase, which catalyzes the carboxylation of acetyl-CoA to form malonyl-CoA and is the rate limiting and committed step of de novo fatty acid biosynthesis (Calvo et al., 2000). Using a combination of transcriptomics and metabolomics, a previous study found that $A C A C A$ was downregulated in the adipose tissue of chickens during fasting compared to fed controls (Ji et al., 2012). A transcriptional analysis of abdominal fat from genetically fat and lean chickens also found that $A C A C A$ was downregulated in lean chickens (Resnyk et al., 2013). The epistatic effect between $A C A C A$ and FABP2 affected the phenotypic variation of abdominal fat content in broilers (Hu et al., 2010). Acyl-CoA synthetase long-chain family member 1 (ACSL1) encodes long-chain fatty acidCoA ligase 1 , which was downregulated in this study. Another previous study showed that microRNA gga-miR19b$3 p$ contributed to the increased accumulation of abdominal fat in Beijing-You chickens by downregulating ACSL1 (Huang et al., 2015). These inconsistent results may be due to the different breeds of chickens used in the two studies. Seven glycerolipid metabolism-associated genes, including PNPLA3, LPIN1, EFCAB4B, PPAP2A, LIPC, FAM126B, and LOC107049382 were identified in this study. This pathway was also identified in abdominal fat tissue between fast and slow growing chickens (Claire et al., 2014). Based on this and previous studies, the fatty acid biosynthesis pathway could be a key vitamin E-regulated pathway that controls abdominal fat metabolism in broilers; and FASN and $A C A C A$ may be key vitamin E-regulated genes that also affect this process.

Insulin and insulin resistance are well-known lipid metabolism-related pathways that play important roles in lipid metabolism and obesity resistance (Saltiel et al., 2001; Kahn et al., 2006). A previous study that analyzed lncRNA and mRNA expression by RNA-seq showed that mTOR and MAPK signaling were active in chicken abdominal preadipocytes at different stages of differentiation (Zhang et al., 2017). Both signaling pathways play essential roles in preadipocyte differentiation and were also identified in this study. Other signaling pathways, including apelin signaling, thyroid hormone, calcium, estrogen, and phospholipase D also play important roles in lipid metabolism, and require further study with regards to their effects on abdominal fat metabolism in broilers.

In conclusion, we found that vitamin $\mathrm{E}$ inhibits abdominal fat deposition in broilers through the fatty acid biosynthesis pathway and we identified key genes that regulate lipid metabolism. It is worth mentioning that the genes encoding the rate-limiting steps of de novo fatty acid synthesis, FASN and $A C A C A$, showed decreased expression in abdominal fat tissue following vitamin $\mathrm{E}$ supplementation. In practice, dietary vitamin $\mathrm{E}$ supplementation is insufficient for boiler chickens, and may lead to more abdominal fat accumulation through regulated genes, especially $F A S N$ and $A C A C A$. Herein, we identified the pathways and genes regulated by vitamin $\mathrm{E}$, thereby providing new insights into vitamin $\mathrm{E}$ regulation of abdominal fat deposition in broilers.

\section{Acknowledgments}

This research was funded by the National Natural Science Foundation of China (31501970), Fujian Province Training Program for Scientific Research Talents of Outstanding Young People of China, Fujian Provincial Natural Science Foundation of China (2017J01640), Students' Team of Mr. Yang Sheng (2016A30020), and Fujian Province Undergraduate Innovation and Entrepreneurship Training Program (201811312052). We thank International Science Editing (http://www.internationalscience-editing.com) for editing this manuscript.

\section{Conflicts of Interest}

The authors declare no conflict of interest.

\section{References}

Alkholy UM, Abdalmonem N, Zaki A, Elkoumi MA, Hashim MIA, Basset MAA and Salah HE. The antioxidant status of coenzyme Q10 and vitamin $\mathrm{E}$ in children with type 1 diabetes. J Pediatr (Rio J). 95: 224-230. 2018.

Azzi A Many tocopherols, one vitamin E. Molecular Aspects of Medicine 61: 92-103. 2018.

Bai S, Wang G, Zhang W, Zhang S, Rice BB, Cline MA and Gilbert ER. Broiler chicken adipose tissue dynamics during the first two weeks post-hatch. Comparative Biochemistry and Physiology - Part A: Molecular \& Integrative Physiology, 189: 115123. 2015.

Bakhtiarizadeh MR, Moradi-Shahrbabak M and Ebrahimie E. Underlying functional genomics of fat deposition in adipose tissue. Gene, 521: 122-128. 2013.

Calvo JH, Lopez-Corrales NL, Anderson SI, Skinner TM, Marcos S, Osta R, Archibald AL and Zaragoza P. Assignment of acetylcoenzyme A carboxylase alpha (ACACA) to pig chromosome $12(12 \mathrm{p} 13$-> p12) by fluorescence in situ hybridization and confirmation by genetic mapping. Cytogenetics and Cell Genetics, 90: 238-239. 2000.

Chambers JR. Genetics of growth and meat production in chickens. Beilstein Journal of Organic Chemistry, 5: 584-584. 2009.

Chen Y, Chen Y, Shi C, Huang Z, Zhang Y, Li S, Li Y, Ye J, Yu C and Li Z. SOAPnuke: a MapReduce acceleration-supported software for integrated quality control and preprocessing of high-throughput sequencing data. Gigascience, 7:gix120. 2018.

Claire DAH, Paul W, Shen X, Jia X, Zhang R, Sun L and Zhang X. Identification and characterization of genes that control fat 
deposition in chickens. Journal of Animal Science and Biotechnology, 4: 22-37. 2014.

Duan J, Shao F, Shao Y, Li J, Ling Y, Teng K, Li H and Wu C. Androgen inhibits abdominal fat accumulation and negatively regulates the PCK1 gene in male chickens. PLoS One, 8: e59636. 2013.

Ferrinho AM, Nassu RT, Aldai N, Bravo-Lamas L, Furlan MLN, Toda BM, Utembergue BL, Rezende RG, Mueller LF, Furlan JJM, Zanata M, Baldi F and Pereira ASC. Whole cottonseed, vitamin $\mathrm{E}$ and finishing period affect the fatty acid profile and sensory traits of meat products from Nellore cattle. Meat Science, 138: 15-22. 2018.

Fu Y, Luo N, Klein RL and Garvey WT. Adiponectin promotes adipocyte differentiation, insulin sensitivity, and lipid accumulation. Journal of Lipid Research, 46: 1369-1379. 2005.

Galli F, Azzi A, Birringer M, Cook-Mills JM, Eggersdorfer M, Frank J, Cruciani G, Lorkowski S and Ozer NK. Vitamin E: Emerging aspects and new directions. Free Radical Biology and Medicine, 102: 16-36. 2017.

Gonzalez-Calvo L, Dervishi E, Joy M, Sarto P, Martin-Hernandez R, Serrano M, Ordovas JM and Calvo JH. Genome-wide expression profiling in muscle and subcutaneous fat of lambs in response to the intake of concentrate supplemented with vitamin E. BMC Genomics, 18: 92. 2017.

Gonzalez-Calvo L, Joy M, Alberti C, Ripoll G, Molino F, Serrano M and Calvo JH. Effect of finishing period length with alphatocopherol supplementation on the expression of vitamin Erelated genes in the muscle and subcutaneous fat of light lambs. Gene, 552: 225-233. 2014.

Götz S, Garcíagómez JM, Terol J, Williams TD, Nagaraj SH, Nueda MJ, Robles M, Talón M, Dopazo J and Conesa A. Highthroughput functional annotation and data mining with the Blast2GO suite. Nucleic Acids Research, 36: 3420-3435. 2008.

Gray B, Swick J and Ronnenberg AG. Vitamin E and adiponectin: proposed mechanism for vitamin E-induced improvement in insulin sensitivity. Nutrition Reviews, 69: 155-161. 2011.

Guo YM, Tang Q, Yuan JM and Jiang ZR. Effects of supplementation with vitamin $\mathrm{E}$ on the performance and the tissue peroxidation of broiler chicks and the stability of thigh meat against oxidative deterioration. Animal Feed Science and Technology, 89: 165-173. 2001.

Habibian M, Ghazi S and Moeini MM. Effects of dietary selenium and vitamin $\mathrm{E}$ on growth performance, meat yield, and selenium content and lipid oxidation of breast meat of broilers reared under heat stress. Biological Trace Element Research, 169: 142-152. 2016.

Hu G, Wang SZ, Tian JW, Chu LL and Li H. Epistatic effect between ACACA and FABP2 gene on abdominal fat traits in broilers. Journal of Genetics and Genomics, 37: 505-512. 2010.

Huang HY, Liu RR, Zhao GP, Li QH, Zheng MQ, Zhang JJ, Li SF, Liang $Z$ and Wen J. Integrated analysis of microRNA and mRNA expression profiles in abdominal adipose tissues in chickens. Scientific Reports, 5: 16132. 2015.

Ji B, Ernest B, Gooding JR, Das S, Saxton AM, Simon J, Dupont J, Metayer-Coustard S, Campagna SR and Voy BH. Transcriptomic and metabolomic profiling of chicken adipose tissue in response to insulin neutralization and fasting. BMC Genomics, 13: 441. 2012.

Jin $\mathrm{P}, \mathrm{Wu} \mathrm{X}, \mathrm{Xu} \mathrm{S}$, Zhang H, Li Y, Cao Z, Li H and Wang S. Differential expression of six genes and correlation with fatness traits in a unique broiler population. Saudi Journal of Biological Sciences, 24: 945-949. 2017.
Kahn SE, Hull RL and Utzschneider KM. Mechanisms linking obesity to insulin resistance and type 2 diabetes. Nature, 444 : 840. 2006.

Kawada T, Aoki N, Kamei Y, Maeshige K, Nishiu S and Sugimoto E. Comparative Investigation of Vitamins and Their Analogs on Terminal Differentiation, from Preadipocytes to Adipocytes, of 3t3-L1 Cells. Comparative Biochemistry and Physiology aPhysiology, 96: 323-326. 1990.

Kim D, Langmead B and Salzberg SL. HISAT: a fast spliced aligner with low memory requirements. Nature Methods 12: 357-360. 2015.

Landrier JF, Gouranton E, Yazidi CE, Malezet C, Balaguer P, Borel $\mathrm{P}$ and Amiot MJ. Adiponectin Expression Is Induced by Vitamin E via a Peroxisome Proliferator-Activated Receptor $\gamma$ Dependent Mechanism. Endocrinology, 150: 5318. 2009.

Langmead B and Salzberg SL. Fast gapped-read alignment with Bowtie 2. Nature Methods, 9: 357. 2012.

Li B and Dewey CN. RSEM: accurate transcript quantification from RNA-Seq data with or without a reference genome. BMC Bioinformatics, 12: 323. 2011.

Li WJ, Zhao GP, Chen JL, Zheng MQ and Wen, J. Influence of dietary vitamin $\mathrm{E}$ supplementation on meat quality traits and gene expression related to lipid metabolism in the Beijing-you chicken. British Poultry Science, 50: 188-198. 2009.

Livak KJ and Schmittgen TD. Analysis of relative gene expression data using real-time quantitative PCR and the 2(T)(-Delta Delta C) method. Methods, 25: 402-408. 2001.

Love MI, Huber W and Anders S. Moderated estimation of fold change and dispersion for RNA-seq data with DESeq2. Genome Biology, 15: 550. 2014.

Niranjan SK, Goyal S, Dubey PK, Kumari N, Mishra SK, Mukesh $\mathrm{M}$ and Kataria RS. Genetic diversity analysis of buffalo fatty acid synthase (FASN) gene and its differential expression among bovines. Gene, 575: 506-512. 2016.

Oliveira CP, Gayotto LC, Tatai C, Della Nina BI, Lima ES, Abdalla DS, Lopasso FP, Laurindo FR and Carrilho FJ. Vitamin C and vitamin $\mathrm{E}$ in prevention of Nonalcoholic Fatty Liver Disease (NAFLD) in choline deficient diet fed rats. Nutrition Journal, 2: 9.2003.

Ouyang J, Xie L, Liu J, Luo Y, Liang Z, Nie Q and Zhang X. Genetic diversity of two sites of FASN gene and its association with growth and fat deposition in chickens. Acta Veterinaria Et Zootechnica Sinica. 38: 25-30. 2007.

Podszun MC, Grebenstein N, Spruss A, Schlueter T, Kremoser C, Bergheim I and Frank J. Dietary alpha-tocopherol and atorvastatin reduce high-fat-induced lipid accumulation and downregulate CD36 protein in the liver of guinea pigs. Journal of Nutritional Biochemistry, 25: 573-579. 2014.

Pompeu MA, Cavalcanti LFL and Toral FLB. Effect of vitamin E supplementation on growth performance, meat quality, and immune response of male broiler chickens: A meta-analysis. Livestock Science, 208: 5-13. 2018.

Resnyk CW, Carré W, Wang X, Porter TE, Simon J, Bihanduval EL, Duclos MJ, Aggrey SE and Cogburn LA. Transcriptional analysis of abdominal fat in chickens divergently selected on bodyweight at two ages reveals novel mechanisms controlling adiposity: validating visceral adipose tissue as a dynamic endocrine and metabolic organ. BMC Genomics, 18: 626. 2017.

Resnyk CW, Carre W, Wang XF, Porter TE, Simon J, Le BihanDuval E, Duclos MJ, Aggrey SE and Cogburn LA. Transcriptional analysis of abdominal fat in genetically fat and lean chickens reveals adipokines, lipogenic genes and a link be- 
tween hemostasis and leanness. BMC Genomics, 14. 2013.

Resnyk CW, Chen C, Huang H, Wu CH, Simon J, Le BDE, Duclos MJ and Cogburn LA. RNA-Seq Analysis of abdominal fat in genetically fat and lean chickens highlights a divergence in expression of genes controlling adiposity, hemostasis, and lipid metabolism. PLoS One, 10: e0139549. 2015.

Saltiel AR and Kahn CR. Insulin signalling and the regulation of glucose and lipid metabolism. Nature, 414: 799-806. 2001.

Sato K, Gosho M, Yamamoto T, Kobayashi Y, Ishii N, Ohashi T, Nakade Y, Ito K, Fukuzawa Y and Yoneda M. Vitamin E has a beneficial efficacy on nonalcoholic fatty liver disease: a metaanalysis of randomized controlled trials. Nutrition, 31: 923. 2015.

Siegel PB, Price SE, Meldrum B, Picard M and Geraert PA. Performance of pureline broiler breeders fed two levels of vitamin E. Poultry Science, 80: 1258-1262. 2001.

Sun YF, Zhang M Li Y and Yang XY. Advances in vitamin E regulation of lipid metabolism in animals. Chinese Journal of Animal Science, 51: 82-85. 2015.

Sun YF, Zhao GP, Liu RR, Zheng MQ, Hu YD, Wu D, Zhang L, Li
$\mathrm{P}$ and Wen J. The identification of 14 new genes for meat quality traits in chicken using a genome-wide association study. BMC Genomics, 14: 458. 2013.

Wakil SJ. Fatty acid synthase, a proficient multifunctional enzyme. Biochemistry, 28: 4523. 1989.

Yan MK and Khalil H. Vitamin Supplements in Type 2 Diabetes Mellitus Management: A Review. Diabetes and Metabolic Syndrome. 11S: S589-S595. 2017.

Zaboli GR. The effect of dietary antioxidant supplements on abdominal fat deposition in broilers. Life Science Journal, 2s: 328-333. 2013.

Zhang T, Zhang, X Han K, Zhang G, Wang J, Xie K and Xue Q. Genome-wide analysis of IncRNA and mRNA expression during differentiation of abdominal preadipocytes in the chicken. G3 (Bethesda), 7: 953-966. 2017.

Zhuo Z, Lamont SJ, Lee WR and Abasht B. RNA-seq analysis of abdominal fat reveals differences between modern commercial broiler chickens with high and low feed efficiencies. PLoS One, 10: e0135810.2015. 